\title{
Compressive Stress-strain Behaviour of Cement Mortar-composites Reinforced with Short Sisal Fibre
}

\author{
Paulo R. L. Lima ${ }^{\mathrm{a} *}$, Romildo D. Toledo Filho ${ }^{\mathrm{b}}$, João A. Melo Filho \\ ${ }^{a}$ Post-graduate Program of Civil and Environmental Engineering, Department of Technology, \\ State University of Feira de Santana - UEFS, Feira de Santana, BA, Brazil \\ ${ }^{\mathrm{b} C i v i l ~ E n g i n e e r i n g ~ D e p a r t m e n t, ~ A l b e r t o ~ L u i z ~ C o i m b r a ~ I n s t i t u t e ~ f o r ~ G r a d u a t e ~ S t u d i e s ~ a n d ~ R e s e a r c h ~ i n ~}$ \\ Engineering - COPPE, Federal University of Rio de Janeiro - UFRJ, CP 68506, \\ CEP 21945-970, Rio de Janeiro, RJ, Brazil \\ ${ }^{\mathrm{C}}$ Civil Engineering Department, Federal University of Amazonas - UFAM, Manaus, AM, Brazil
}

Received: September 1, 2012; Revised: October 3, 2013

\begin{abstract}
To design building elements using sisal fibre reinforced mortar composites, the stress-strain curves of the composites both under tensile and compression load is needed. In this study short sisal fibre-cement based composites were developed and their stress-strain behaviour under compression characterized experimentally. The composites consisted of two mortar matrices, one self-compacting and one of normal consistency, reinforced with randomly distributed short sisal fibre (25 and $50 \mathrm{~mm}$ long) in volume fractions ranging from $2 \%$ to $6 \%$. Based on the experimental results a compressive constitutive law for the composites was proposed based on the damage theory developed by Mazars (1986). This theory was used to model the ascending branch of the stress-strain curve and a damage parameter associated to the fibre-reinforcing index is proposed to allow the modelling of the post-peak behaviour of the composites. The modified model was then validated using results available in the literature. The experimental results obtained in the study indicated that the addition of short sisal fibres to cement matrices tends to reduce its elastic modulus, peak stress and strain and to increase its toughness. However, the use of a self-compacting matrix allowed better sisal fiber dispersion and composites with superior performance were obtained. The modified analytical model was able to predict with good accuracy the ascending and descending branch of the stress-strain curves of the sisal fiber-mortar composites and allowed evaluating the effect of fibre reinforcing index on material damage. In the ascending branch, an increase in the damage from $40 \%$ to $70 \%$ is recorded for fiber volume ranging from 2 to $6 \%$. In the descending branch, on the other hand, the variation of fiber volume allowed a reduction of the damage from $65 \%$ to $60 \%$.
\end{abstract}

Keywords: sisal fibre, stress-strain behaviour, compressive loads, damage model

\section{Introduction}

The application of vegetable fibres as reinforcement of cement based composite materials is an ancient practice that has seen its interest renewed world-wide ${ }^{1-3}$ after studies have indicated solutions for minimizing the early deterioration of these fibres in the alkaline ambient of cement matrices ${ }^{4}$. In addition, the energy and cost for production of these fibres are low when compared to those of glass and polymeric fibres. This type of composite is particularly interesting for countries where exist a great availability of vegetable fibres. Considering the enormous variety and abundance of lignocellulosic fibres existing in $\mathrm{Brazil}^{5}$ this type of material can be of great interest for the construction industry. Amongst the several vegetable fibres available in the country sisal fibre is of particular importance. This fibre is obtained from a plant that is very well adapted to the semi-arid region of Brazil where, due to the low amount of rainfall and soil characteristics, not many plants can grow. The development of high performance sisal fibre-composites

*e-mail: lima.prl@pq.cnpq.br for application in the construction industry is twofold once it can improve the economy of this region creating job opportunities for low skilled labour and help in the combat of the desertification phenomena that is already observed in some parts of this region.

Short sisal fibre mortar-composites was already considered for concrete roofing in several parts of the world ${ }^{6,7}$. However, the sensitive of this fibre to the alkaline environment of the Portland cement matrix limited it's application. In addition, the hydrophilic nature of this fibre associated with the rheological characteristics of the used matrices limited the fibre volume fraction to $2-3 \%$ due to the difficulty in material mixing and casting without increasing the water content in the mixtures ${ }^{8}$. The fibre length was limited to 25-30 $\mathrm{mm}$ due to the risk of fibre balling during the mixing procedure 9 .

The main benefit related to the use of lignocellulosic fibres as reinforcement in cement matrices is the increment in toughness, post-cracking performance and resistance to 
impact of the material ${ }^{8-11}$. On the other hand, vegetable (sisal) fibre has a negative influence on the stress-strain behaviour under compression loads of the cement matrix. Results ${ }^{10,11}$ indicate a reduction in the compressive strength and elastic modulus and an increase in the porosity of the matrix with the increase in the content of short vegetable fibre present in the mixture. The magnitude of the reduction in the composite properties depends, however, on the reinforcement characteristics (e.g. type of vegetable fibre, volume fraction and fibre length), matrix characteristics (e.g. maximum sand size, matrix rheology and strength), and composite processing (e.g. type of mixer used, intensity of energy used in the mixing process).

To minimize the damage in the composite properties, appropriate matrices have to be designed to enable a good dispersion of the short fibres. The changes in the matrix are primarily associated with the control on the grain size of sand, sand/cement ratio, the type and quantity of mineral admixtures and the use of plasticizers/superplasticizers additives and viscosity modifying agents ${ }^{12-13}$.

In this paper the influence of sisal fibre volume fraction $(1 \%, 2 \%, 3 \%, 4 \%$ and $6 \%)$, fibre length (25 $\mathrm{mm}$ and $50 \mathrm{~mm})$ and cement matrix workability on the compressive stressstrain behaviour of cement mortar composites is evaluated experimentally. Two mortars of different rheology were used as matrices: a mortar mixture with a flow table spreading of $310 \pm 10$ and a self-compacting mixture. The latter was designed with a large quantity of pozzolanic materials in its composition in order to obtain a matrix free of calcium hydroxide and a composite of improved durability as suggested by ${ }^{3,14,15}$.

Several empirical equations have been proposed for the analysis of stress-strain behaviour of cement matrices ${ }^{16}$ and vegetable fibre reinforced cement composites ${ }^{17-18}$ but usually many experimental parameters are needed for their use. Models based on damage mechanics have gain interest for the modelling of the stress-strain curve of conventional concrete $^{19-21}$ due to the ease of analysis and numerical implementation. Besides the experimental investigation described above, this paper also aims to present an analytical model to predict the complete stress-strain curve of sisal fiber reinforced mortar based on the damage theory proposed by Mazars ${ }^{19}$. The main modifications in the model, originally conceived to simulate the damage behaviour of ordinary concrete, were the inclusion of damage parameters associated to the fibre-reinforcing index and the definition of a new scalar damage variable to allow the modelling of the post-peak behaviour of the composites. To show the robustness of the model it is validated using experimental results available in the literature.

\section{Experimental program}

\subsection{Material}

The sisal fibre (Agave sisalana) used in this investigation was produced in the state of Bahia, Brazil. They were washed in hot water $\left(50^{\circ} \mathrm{C}\right)$ to remove superficial oils and greases that affect the hydration of the cement, brushed to separate the individual fibres and cut to the sizes of $25 \mathrm{~mm}$ and $50 \mathrm{~mm}$. The fibre volume fraction used in this work ranges from $1 \%$ to $6 \%$. Sisal fibres from this region were largely characterized by Toledo Filho ${ }^{11}$ and had a high tensile strength (about $577 \mathrm{MPa}$ ) and a low modulus of elasticity (19 GPa). Despite having an irregular cross section their diameter is estimated at $0.12 \mathrm{~mm}^{10}$.

Two mortar matrices were produced in the study using different types of binder and fine aggregates: a mortar mixture designed for a consistency of $310 \pm 10 \mathrm{~mm}$ in the flow table test, named conventional matrix M1, and a selfcompacting mixture named matrix M2.

The M1 matrix was produced using Portland cement type CP-III (ASTM type IS), river sand with maximum particle size of $4.8 \mathrm{~mm}$, fineness modulus of 2.7 , density of $2.60 \mathrm{~g} / \mathrm{cm}^{3}$ and tap water.

The matrix M2 was produced using a blend of $50 \%$ of Portland cement type CP-II (ASTM Type I-MP) and 50\% of metakaolin (mass proportion), river sand with density of $2.64 \mathrm{~g} / \mathrm{cm}^{3}$, maximum particle size of $0.6 \mathrm{~mm}$ and fineness modulus of 2.2 and tap water. Naphthalene based superplasticizer with solid content of $44 \%$ were also used to ensure an adequate fluidity.

Figure 1 shows the granulometric curves of the used materials. The chemical composition and density of the binders are shown in Table 1.

Both mortars had a binder/sand ratio of 1:1 (by weight). This binder/sand ratio was selected based on the previous experience of the group $p^{3,4,10,11,15}$ and in the production of fibre cement tiles ${ }^{6}$. The water/cement ratio, superplasticizer content and fibre volume fraction added to each mortar matrix is presented in Table 2 .

\subsection{Production method}

The composites were produced using a bench-mounted mechanical mixer with a capacity of $20 \mathrm{dm}^{3}$ and according to the following procedure. Initially, $40 \%$ of the total water required was added to the pre-homogenised powders of the mixtures (sand and binders) in the running mixer. In order to avoid clumping of fibres and to keep the mix sufficiently wet, the fibres and a further $35 \%$ of the water were slowly added. After placing all the fibres, the remaining water was added to the running mixer that was allowed to continue for

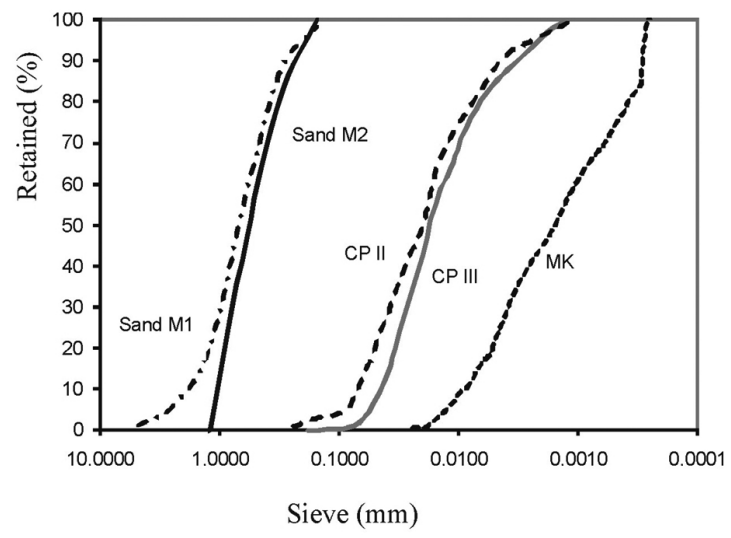

Figure 1. Granulometric curves of each cement type, metakaolin and sands used in the composite production. 
about 5 minutes in order to enhance fibre dispersion. For the mixtures of series M2 the superplasticizer was added with initial water.

The flow table test (ASTM C230) ${ }^{22}$ was carried out to determine the consistency of the matrix M1. A spreading of $317 \mathrm{~mm}$ was observed for this mix. In the case of the self-compacting matrix (M2) a similar spreading $(310 \mathrm{~mm})$ was observed after the mould removal without application of drops in the flow table indicating the high flowability of this matrix.

The samples for the compressive tests were cast in three layers in a cylinder of $100 \mathrm{~mm}$ height and $50 \mathrm{~mm}$ diameter. External vibration was carried out using a vibrating table. The specimens were covered in their moulds with a damp cloth and a polythene sheet for 24 hours. After this period they were removed from the moulds and cured for 28 days in water at $22{ }^{\circ} \mathrm{C}$.

\subsection{Test procedure}

Uniaxial compression tests were carried out on a $1000 \mathrm{kN}$ Shimadzu testing machine at a rate of axial displacement of $0.2 \mathrm{~mm} / \mathrm{min}$. The longitudinal displacements were measured using two electrical transducers (LVDT's) mounted in the central zone of the samples (see Figure 2a). Load and displacements were continuously recorded using a 16-bit

Table 1. Chemical composition and density of the used binders.

\begin{tabular}{cccc}
\hline \multirow{2}{*}{ Compound } & \multicolumn{2}{c}{ Chemical composition (\%) } \\
\cline { 2 - 4 } & $\begin{array}{c}\text { Cement } \\
\text { CP II }\end{array}$ & Metakaolin & $\begin{array}{c}\text { Cement } \\
\text { CP III }\end{array}$ \\
\hline $\mathrm{SiO}_{2}$ & 19.98 & 51.20 & 24.94 \\
$\mathrm{Al}_{2} \mathrm{O}_{3}$ & 3.70 & 35.30 & 7.50 \\
$\mathrm{TiO}_{2}$ & - & 0.41 & - \\
$\mathrm{Fe}_{2} \mathrm{O}_{3}$ & 3.12 & 4.00 & 2.62 \\
$\mathrm{P}_{2} \mathrm{O}_{5}$ & - & 0.20 & - \\
$\mathrm{CaO}$ & 62.80 & 2.62 & 53.05 \\
$\mathrm{MgO}_{\mathrm{K}} \mathrm{O}$ & 3.10 & 0.40 & 5.34 \\
$\mathrm{Na}_{2} \mathrm{O}$ & 0.80 & 0.97 & 0.85 \\
$\mathrm{Loss}(\%)$ & 0.07 & - & 0.12 \\
Density $\left(\mathrm{g} / \mathrm{cm}^{3}\right)$ & 4.93 & - & 2.63 \\
\hline
\end{tabular}

Table 2. Composition of the composites produced in the study.

\begin{tabular}{ccccc}
\hline Mix & Water/binder ratio & $\begin{array}{c}\text { SP } \\
(\%)\end{array}$ & $\begin{array}{c}\text { Vf } \\
(\%)\end{array}$ & $\begin{array}{c}\text { Lf } \\
(\mathbf{m m})\end{array}$ \\
\hline M1 & & - & 0 & - \\
M1S125 & 0.40 & - & 1 & 25 \\
M1S225 & & - & 2 & 25 \\
M1S325 & & - & 3 & 25 \\
\hline M2 & & 1.0 & 0 & - \\
M2S225 & 0.45 & 1.5 & 2 & 25 \\
M2S425 & & 2.5 & 4 & 25 \\
M2S625 & & 3.0 & 6 & 25 \\
M2S250 & & 1.5 & 2 & 50 \\
M2S450 & & 2.5 & 4 & 50 \\
\hline
\end{tabular}

data acquisition system taking 2 readings/second. The chord modulus of elasticity was calculated from the stress-strain diagram as recommended by ASTM C $469^{23}$. The chord modulus is the slope of the line drawn between two fixed points on the stress-strain diagram. The lower point is the point where the strain is 0.000050 while the upper point is the point where the stress is $40 \%$ of the peak stress.

The compressive toughness, energy absorbed by the composites when subjected to the compression loads, was evaluated measuring the area under the stress-strain curve. Some researchers ${ }^{24}$ quantify the ductility of fibre concrete comparing this area with a similar rigid plastic material. In this work, the toughness index under compression $\left(\mathrm{I}_{\mathrm{T}}\right)$ is proposed as the ratio of the area of the stress-strain curve up to the strain of $6000 \mu \varepsilon$ (curve OPQC in Figure 2b) divided by the area of the stress-strain curve of an ideal elastic-plastic material (curve OABC in Figure 2b) with the same elastic modulus and peak stress of the composite.

\section{Experimental Results}

\subsection{Stress-strain behaviour}

Typical examples of stress-strain curves for the matrix and sisal fibre reinforced mortar are presented in Figure 3. Table 3 presents the mean values of three specimens and the coefficient of variation (by \%), in parenthesis, of the peak stress, peak strain, elastic modulus and compression toughness index.

The stress-strain curve of the composite loaded under compression is characterized by an ascending branch up to the peak stress, followed by a descending branch. Despite of the presence of small micro-cracks present in the matrix before loading, these micro-cracks will not propagate at relative low loads and the microstructure can be stationary. The increment of load results in a variation of internal stiffness and stress with a progressive microcrack growth. The microcracks initiate at the paste-aggregate interface and subsequently propagate into the cement paste, as can be seen in Figure 4a, and form continuous macrocracks around the peak stress of the stress-strain curve. At this point, crack growth becomes unstable, and when the strength is achieved, spontaneous fracture of the specimen would occur after some time ${ }^{25}$. After the peak stress, in a deformationcontrolled test, this macrocrack growth results in a softening and localization of cracking. This localization means that no further crack will appear, but a decrease of load due to crack opening ${ }^{26}$.

The crack growth in cement matrix loaded in compression results in a crack pattern which divides the sample into a number of triangular or conical pieces which can shear off, as shown in Figure 5. Essentially the two crack faces are connected by a ligament between overlapping crack tips thus allowing the stress transfer between the crack faces and a gradual reduction of strength with an increment of deformation. The type of crack overlapping observed in cement materials is called "crack interface bridging", according to $\mathrm{Van} \mathrm{Mier}^{27}$, and the carrying capacity of the crack depends on the crack width. The pos-peaking branch is represented by an abrupt reduction of stress which 


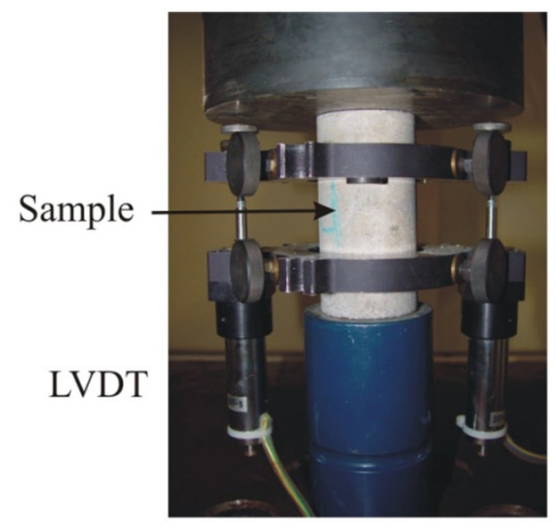

a)

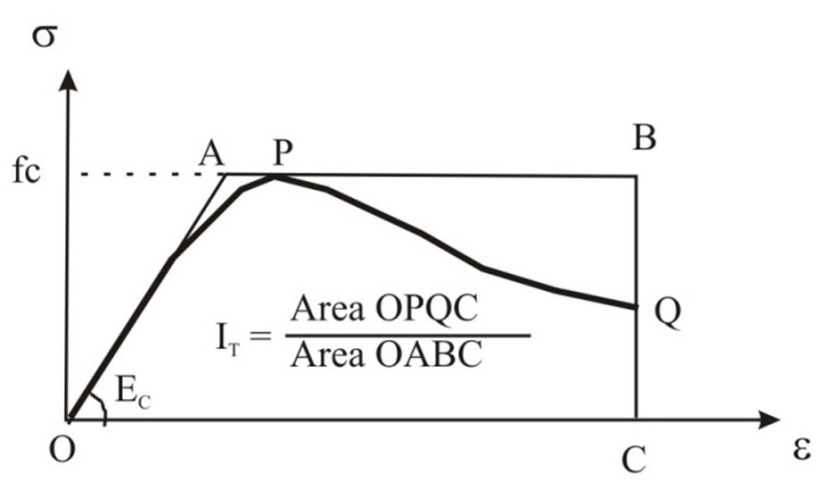

b)

Figure 2. Test procedures: a) uniaxial compression testing setup; b) definition of the compression toughness index $\left(\mathrm{I}_{\mathrm{T}}\right)$.
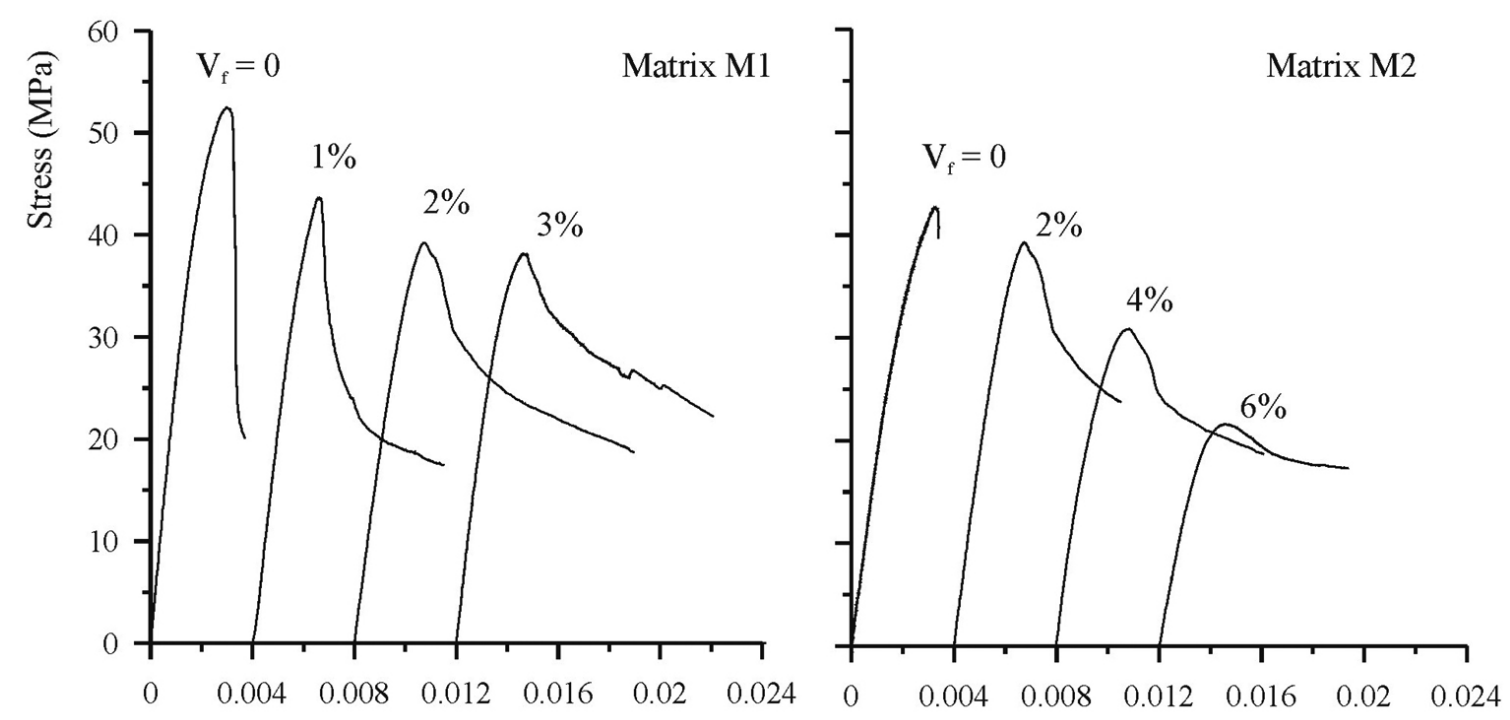

\section{Strain $(\mathrm{mm} / \mathrm{mm})$}

Figure 3. Typical stress-strain curves for the composites reinforced with $25 \mathrm{~mm}$ long sisal fibre.

Table 3. Peak stress and strain, elastic modulus and toughness of the studied composites.

\begin{tabular}{ccccc}
\hline Mix & Peak stress (MPa) & $\begin{array}{c}\text { Peak strain } \\
(\mu \varepsilon)\end{array}$ & $\begin{array}{c}\text { Elastic } \\
\text { Modulus }(\mathbf{G P a})\end{array}$ & $\begin{array}{c}\text { Toughness } \\
\text { Index }\end{array}$ \\
\hline M1 & $51.60(1.8)$ & $3073.2(3.7)$ & $25.9(1.4)$ & $0.48(1.8)$ \\
M1S125 & $42.50(3.2)$ & $2688.6(3.9)$ & $21.8(4.2)$ & $0.76(11.1)$ \\
M1S225 & $38.00(3.6)$ & $2594.0(3.0)$ & $20.3(5.5)$ & $0.80(6.4)$ \\
M1S325 & $37.50(2.3)$ & $2643.9(4.4)$ & $21.1(1.9)$ & $0.86(3.3)$ \\
M2 & $43.30(8.5)$ & $3285.7(11.7)$ & $18.6(2.1)$ & $0.43(13.1)$ \\
M2S225 & $39.86(5.9)$ & $3176.88(11.8)$ & $18.6(2.5)$ & $0.76(7.5)$ \\
M2S425 & $30.41(1.5)$ & $3036.50(6.0)$ & $16.4(12.4)$ & $0.91(7.0)$ \\
M2S625 & $21.22(2.1)$ & $2755.74(5.6)$ & $13.4(1.3)$ & $0.93(2.1)$ \\
M2S250 & $32.26(4.8)$ & $2308.83(10.2)$ & $16.3(3.7)$ & $0.78(11.0)$ \\
M2S450 & $24.80(2.3)$ & $2426.15(7.6)$ & $15.3(3.8)$ & $0.87(1.4)$ \\
\hline
\end{tabular}



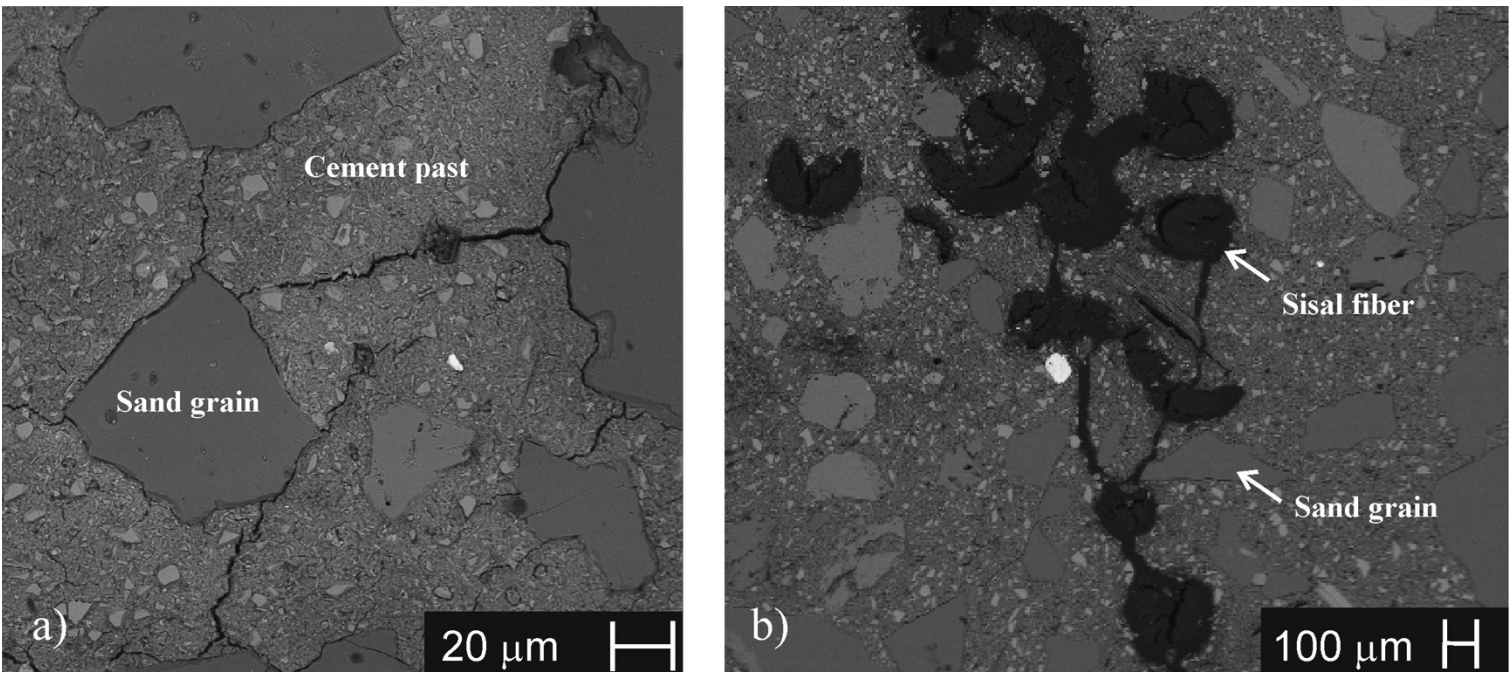

Figure 4. SEM of internal cracking: a) matrix; b) composite $^{10}$.

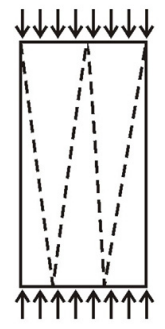

(a)

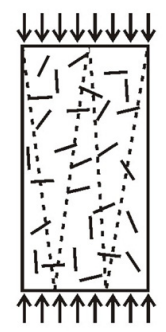

(b)

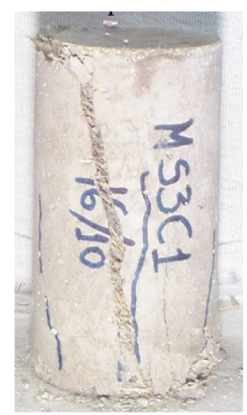

(c)
Figure 5. Rupture mechanism under compression: (a) matrix; (b) effect of fibre reinforcement; c) typical fracture mode of the composites.

characterizes the cement matrix as brittle material, as shown in Figure 3.

The effect of short sisal fibres on the stress-strain behaviour of the matrices can be divided in two parts. In the pre-peak zone, the addition of sisal fibre tends to reduce the peak stress and elastic modulus of the matrix (see Table 3 ). In the postpeak zone when the crack face bridging by grains fails, stress transfer over the crack is possible through fibres intersecting with the crack (see Figure $4 \mathrm{~b}$ and Figure 5). Toughening in the natural fibre-reinforced composites occurs largely as a result of crack bridging ${ }^{28}$. The presence of discontinuous fibres in the concrete reduces the unstable propagation of macrocracks and permits a ductile post-peak behaviour once the fibres can provide sufficient forces to suppress crack opening and redistribute the stresses onto the nearby matrix, thus suppressing strain localization ${ }^{29}$. As a result, the post-peak behaviour of the composite is more ductile than that of the plain matrix with a gradual reduction of strength in this branch as shown in Figure 3. Therefore, the addition of fibre results in an increment of toughness of material, with a greater energy absorption, and a better distributed cracking.

\subsection{Influence of fibre volume fraction and type of matrix}

In Table 3 the effect of sisal volume fraction and fibre length on the mechanical properties of both composite families is presented. In both cases a reduction in the peak stress, peak strain and elastic modulus is verified with the increment of fibre content. For mixes M1S125, M1S225 and M1S325, for example, the increase in fibre content from $1 \%$ to $3 \%$ reduced the peak stress of the matrix M1 by about $8 \%$ to $25 \%$, respectively. For the same fibre content, the elastic modulus was reduced by about $6 \%$ to $20 \%$ and the peak strain reduced by $14 \%$ to $33 \%$, compared to the matrix properties. Two main factors contribute to this behaviour: i) the introduction of a low modulus inclusion (sisal fibre) in the mixtures and ii) an increase in the matrix porosity due to the reduction of the workability of the mixture with the increase in the fibre volume fraction. The increase in porosity may be related to an insufficient compaction and a possible additional number of micro-cracks may be related to touching fibres, unbounded fibres and cracks or poor fibre/matrix bonding ${ }^{30}$.

The compression toughness index, on the other hand, is significantly increased with the increase in fibre content. For example, the mixture M1S325 presents a $\mathrm{I}_{\mathrm{T}}$ value that is nearly $80 \%$ higher than that observed for the reference mixture M1.

For the mixtures produced with matrix M2 the reduction of the mechanical properties was proportionally minor with the increase of the fibre volume fraction. For example, the addition of $2 \%$ of $25 \mathrm{~mm}$ long sisal fibre shows little effect on the peak stress and strain (reductions inferior to 8\%) and did not affect the elastic modulus of the matrix. With the increment of the volume fraction to $4 \%$ and $6 \%$, the compressive strength is reduced about $30 \%$ and $50 \%$, respectively. The elastic modulus and strain at peak load show maxima reduction of, respectively, $28 \%$ and $16 \%$. As observed for matrix M1, the compression toughness of matrix M2 was significantly improved with the increase in 
fibre content. For example, the mixture M2S625 presents a $\mathrm{I}_{\mathrm{T}}$ value that is nearly $120 \%$ higher than that observed for the reference mixture $\mathrm{M} 2$.

The superior performance of the composites originated from the matrix M2, when compared to those originated from the matrix M1, is associated with a better dispersion of fibres and less incorporation of air during casting which results in a more homogeneous material. It's important to mention that the better workability of the self-compacting matrix allowed the production of composites reinforced with a fibre volume fraction of $6 \%$ (for a fibre length of $25 \mathrm{~mm}$ ) whereas for the matrix M1 the maximum volume fraction that was possible to use in the premix process was $3 \%$.

\subsection{Influence of fibre length}

Figure 6 shows typical normalized (in relation to the peak stress) stress-strain curves for the composites produced with the matrix M2. The results indicate that for both volume fractions the composites reinforced with longer fibre $\left(\mathrm{L}_{\mathrm{f}}=50 \mathrm{~mm}\right)$ presented a worst behaviour under compressive loads. For example, for the sisal fibre content of $2 \%$ the peak stress, elastic modulus and peak strain of the mixture M2S225 are 19\%, 12\% and 27\% higher than those of mixture M2S250. The toughness index, on the other hand, is less affected by the increase in the fibre length and only minor modifications (inferior to $2-5 \%$ ) in this property were observed.

Figure 7 shows the variation of the compressive strength and toughness index of the studied composites with the reinforcement index (Vf.Lf/df). Observing this figure is clear that, for both families of composites studied, there is a tendency of increase in the toughness index and of reduction in the peak stress with the increase in the reinforcement index.

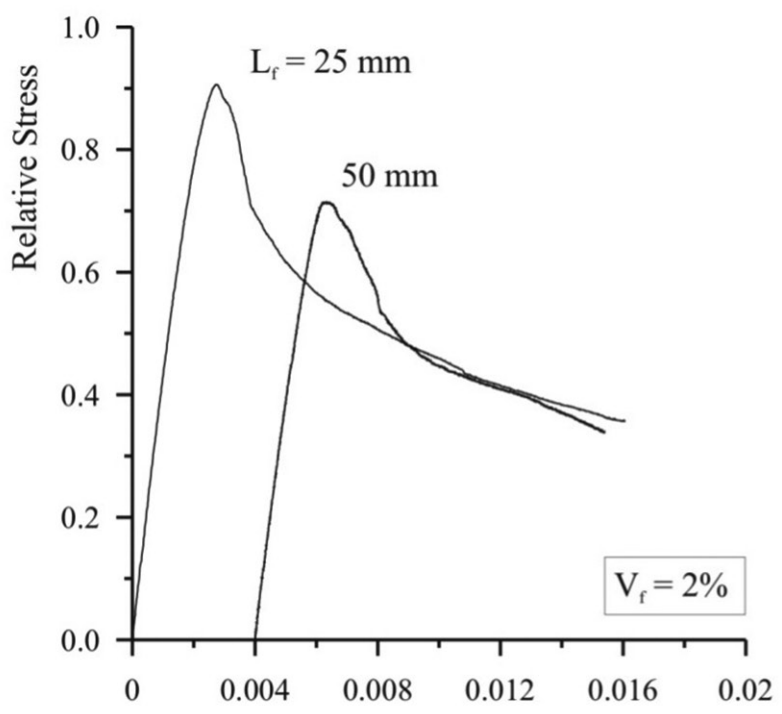

\section{Analytical Modeling}

\subsection{Damage equation}

The concept of damage mechanics applied to quasibrittle materials combines the strain-stress relationship from linear elasticity with the definition of an "effective elastic modulus" 31 . In the damage model, which describes damage due to uniaxial extensions, the loss of stiffness of concrete is represented by a parameter $\mathrm{D}$, according to:

$E=E_{o}(1-D)$

where E represents the ordinary elastic modulus of the material, Eo is the elastic modulus of the undamaged and intact material and D is the scalar damage variable. According to Lemaitre and Mazars ${ }^{20}$ :

$D=1-\frac{\varepsilon_{d o}(1-A)}{\varepsilon_{e q}}-\frac{A}{e^{B\left(\varepsilon_{e q}-\varepsilon_{d o}\right)}}$

where $\mathrm{A}$ and $\mathrm{B}$ are material dependent parameters and $\varepsilon_{d o}$ is the initial damage threshold. $\varepsilon_{e q}$ is the equivalent strain given by $v \sqrt{2 \varepsilon}$ where $v$ is the Poisson ratio of the matrix. The parameter $\mathrm{D}$ is the damage variable for compression that ranges between 0 (if $\varepsilon_{e q}<\varepsilon_{d o}$ ) and 1 (for the completely damaged material with no stiffness).

The damage model shows that the equation offers a good fit for the data up to the point of maximum compressive stress. After peak stress, this model considers that the accumulation of damage no longer results from the growth of a network of cracks, but rather from their coalescence into a macrocrack, that leads to the failure of the solid. Due to this, the softening branch of the curve is not significantly affected by the variation of parameters A and B in Equation 2. In fact, according to Mazars ${ }^{19}$, the combination of damage

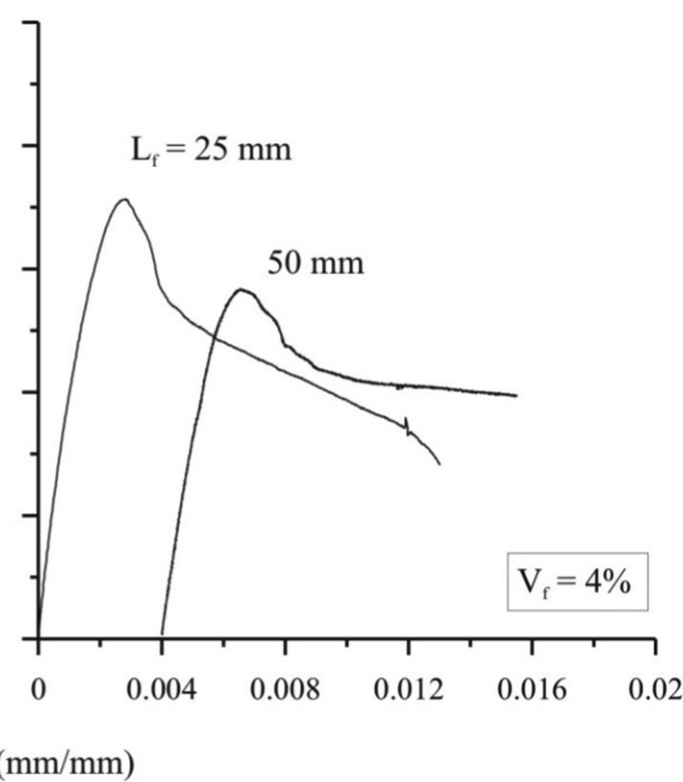

Strain $(\mathrm{mm} / \mathrm{mm})$

Figure 6. Effect of fibre length on stress-strain behaviour of the composites produced using the matrix M2. 


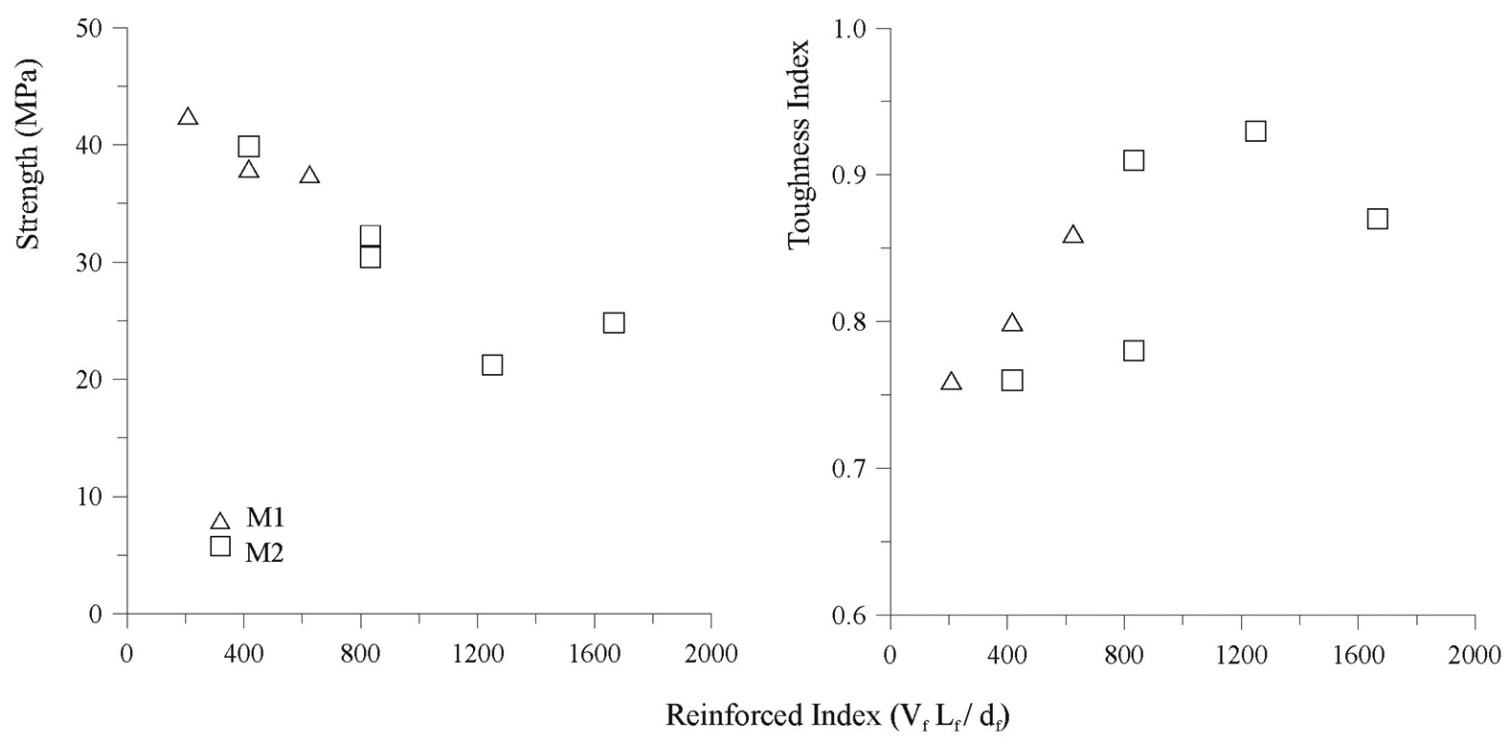

Figure 7. Influence of the reinforcement index on the toughness index and compressive strength of the composites.

mechanics (until peak stress to obtain the beginning of a crack) and fracture mechanics (after peak stress to obtain the continuation of the global behaviour) is more adequate to describe the total stress-strain behaviour of plain concrete.

To fibre reinforced concrete, however, the post-peak behaviour is still characterized by the propagation of stable microcrack and the damage concept can be used to describe the total behaviour. How the fibre addition results in modifications in the descending branch (softening behaviour) another equation should be developed to describe it in a correct mode. Considering that experimental results shown in this work indicate that the stress-strain behaviour of sisal fibre reinforced composites after peak can be described by an exponential equation, the new equation for scalar damage variable, for post-peak branch, is given by:

$D_{p}=1-\left(\frac{\varepsilon_{p}}{\varepsilon_{e q}}\right)^{C}$

where $\varepsilon_{p}$ represents strain at stress peak and $\mathrm{C}$ is a material damage dependent parameter. The constitutive stress-strain equations for the composite are given by:

$\sigma=\left\{\begin{array}{l}E_{o}(1-D) \varepsilon \text { if } \varepsilon \leq \varepsilon_{p} \\ E_{p}\left(1-D_{p}\right) \varepsilon \text { if } \varepsilon>\varepsilon_{p}\end{array}\right.$

where $E_{\mathrm{p}}$ is the secant elastic modulus to the strain at peak stress, calculated using Equations 1 and 2 with $\varepsilon=\varepsilon_{p}$ :

$E_{p}=E_{o}\left(1-\frac{\varepsilon_{d o}(1-A)}{v \sqrt{2 \varepsilon_{p}}}-\frac{A}{\left.e^{B\left(v \sqrt{2 \varepsilon_{p}}-\varepsilon_{d o}\right.}\right)}\right)$

\subsection{Application of the model to the composites reinforced with sisal fibre}

Using the experimental results for the composites produced with the self compacting matrix M2, regression equations were performed to obtain the $\mathrm{A}, \mathrm{B}$ and $\mathrm{C}$ parameters of Equations 1-4. Composite parameters $\left(A_{c}, B_{c}\right)$ are linearly correlated with matrix parameters (A, B) according to Equations 6, 7. The correlation coefficient (R2) is higher than $90 \%$.

$$
\begin{aligned}
& \frac{A}{A_{c}}=-0.00021 V_{f} \frac{L_{f}}{d_{f}}+1.02429\left(\mathrm{R}^{2}=0.98\right) \\
& \frac{B}{B_{c}}=-0.00034 V_{f} \frac{L_{f}}{d_{f}}+1.02308\left(\mathrm{R}^{2}=0.96\right) \\
& C=-0.00029 V_{f} \frac{L_{f}}{d_{f}}+1.69615\left(\mathrm{R}^{2}=0.90\right)
\end{aligned}
$$

The parameters of the strain-stress curve are related to the reinforced index (Vf.Lf/df) because the fibre content, fibre length and diameter are normally known ${ }^{18,29,32}$.

Figure 8 shows a comparison of the experimental and the analytical stress-strain curves for a few representative cases. For the studied M2 matrix the following values were obtained from the experimental data and used in the analysis: $\mathrm{A}=1.90, \mathrm{~B}=1000, \varepsilon_{d o}=0.00035, \mathrm{E}_{\mathrm{o}}=18600 \mathrm{MPa}$ e $v=0.20$. The composite parameters were obtained from Equations 6-8 using data of Table 3. The sisal fibre diameter was considered as $0.12 \mathrm{~mm}^{[10]}$.

Observing the results presented in Figure 8 it can be seen that the used model was capable to predict with accuracy both the ascending and descending branch of the stress-strain curves of the composites reinforced with vegetable (sisal) fibres.

The use of Equations 2 and 3 also permits to evaluate the effect of fibre on material damage, as shown in Figure 9. As discussed, in the pre-peak zone the addition of sisal fibre reduced the mechanical properties of the matrix. It is observed an increment of damage variable $\mathrm{D}$ proportional to 


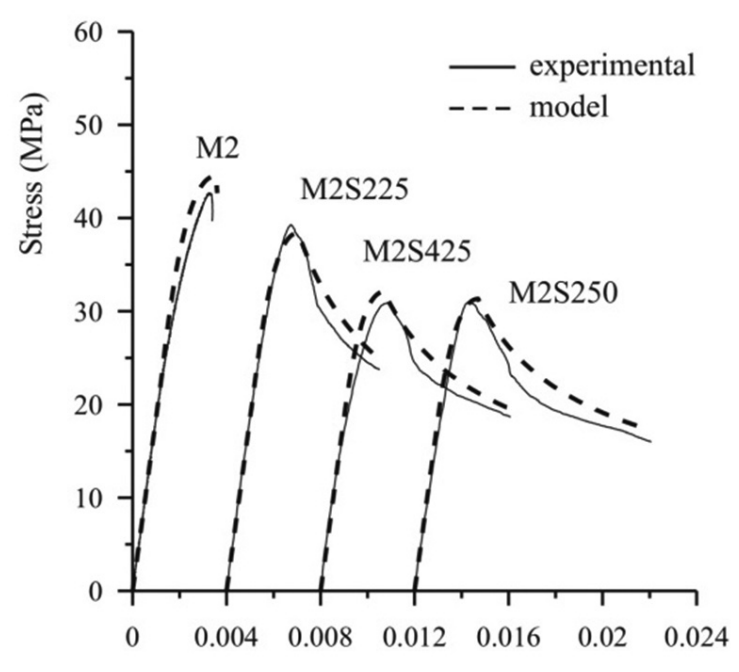

Strain $(\mathrm{mm} / \mathrm{mm})$

Figure 8. Experimental and analytical stress-strain curves for appropriate matrix.

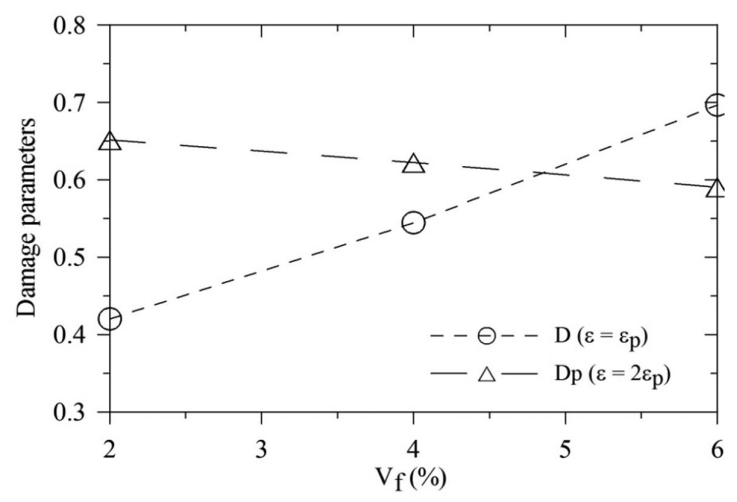

Figure 9. Effect of fibre content on the damage parameters $\mathrm{D}$ and $\mathrm{D}_{\mathrm{p}}$.

the fibre content, to the same level of strain. However, in the post-peak zone the fibres can act as an additional bridging mechanism and the postpeak damage $\mathrm{D}_{\mathrm{p}}$ is reduced with an increase of fibre content, as shown in Figure 9.

\subsection{Experimental validation using literature data}

To validate the model, experimental results by Ferreira ${ }^{33}$ were compared with the analytical stress-strain curve obtained by applying the Equations 1-8. The following values were used based on the experimental data of Ferreira ${ }^{33}$ $\mathrm{A}=1.90, \mathrm{~B}=950, \varepsilon_{d o}=0.00015, \mathrm{E}_{\mathrm{o}}=13270 \mathrm{MPa}$ e $\mathrm{v}=0.20$. The author has used a sisal volume of fibre of $2 \%$ and fibre lengths of $25 \mathrm{~mm}$ and $50 \mathrm{~mm}$. Figure 10 shows a comparison between the experimental and analytical results and a good agreement is observed.

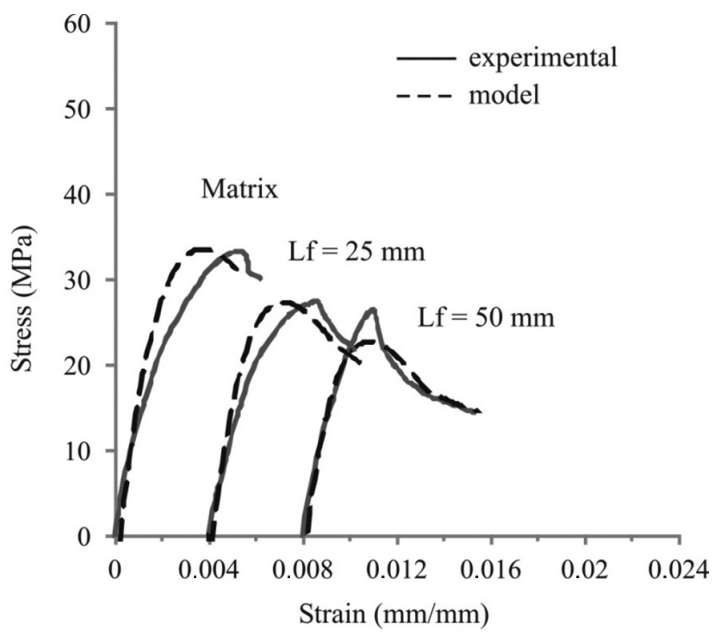

Figure 10. Validation of the damage model using experimental results obtained by Ferreira ${ }^{33}$.

\section{Conclusions}

From the experimental and analytical data presented in this work the following conclusions can be obtained:

- The addition of short sisal fibres to cement matrices tends to reduce the peak stress, strain at failure and elastic modulus of the matrix and increase the toughness of the matrix. The higher the volume fraction used more these properties are affected;

- The elastic properties (peak stress, elastic modulus and peak strain) of the composites reinforced with $50 \mathrm{~mm}$ long sisal fibre were smaller than those obtained for the mixtures reinforced with $25 \mathrm{~mm}$ long fibre. The toughness index, on the other hand, was less affected by the increase in the fibre length;

- The use of a self-compacting matrix allowed the production of composites with better strain-strain response due to the better dispersion of the fibres in the mixture and the reduction of incorporated air during mixing;

- There is an increment in the damage parameter D and a reduction in the parameter $\mathrm{Dp}$ with the increase the fibre volume fraction.

The analytical model proposed in the present study was capable to predict with accuracy both the ascending and descending branch of the stress-strain curves of the composites reinforced with vegetable (sisal) fibres and also allows evaluating the effect of fibre content on material damage.

\section{Acknowledgments}

The authors gratefully acknowledge the financial supporting given by Brazilian CNPq, FAPESB and CAPES. 


\section{References}

1. Elsaid A, Dawwod M, Seracino R and Bobko C. Mechanical properties of kenaf fibre reinforced concrete. Construction and Building Materials. 2011; 25(4):1991-2001. http://dx.doi. org/10.1016/j.conbuildmat.2010.11.052

2. Morton JH, Cooke T and Akers ASA. Performance of slash pine fibres in fibre cement products. Construction and building materials. 2010; 24(2):165-170. http://dx.doi.org/10.1016/j. conbuildmat.2007.08.015

3. Silva FA, Toledo Filho RD, Melo Filho JA and Fairbairn EMR. Physical and mechanical properties of durable sisal fibre-cement composites. Construction and Building Materials. 2010; 24(5):777-785. http://dx.doi.org/10.1016/j. conbuildmat.2009.10.030

4. Toledo Filho RD, Ghavami K, England GL and Scrivener K. Development of vegetable fibre-mortar composites of improved durability. Cement and Concrete Composites. 2003; 25(2):185-196. http://dx.doi.org/10.1016/ S0958-9465(02)00018-5

5. Satyanarayana KG, Guimarães JL and Wypych F. Studies on lignocellulosic fibres of Brazil. Part I: Source, production, morphology, properties and applications. Composites Part A: Applied Science and Manufacturing. 2007; 38(7):1694-709. http://dx.doi.org/10.1016/j.compositesa.2007.02.006

6. Gram HE. Natural fibre concrete roofing. In: Natural fibre reinforced cement and concrete, Vol. 5. London: Blackie and Son Ltd; 1988. p. 256-85.

7. Savastano H, Agopyan V, Nolasco A and Pimentel L. Plant fibre reinforced cement components for roofing. Construction and Building Materials. 1999; 13(8):433-8. http://dx.doi. org/10.1016/S0950-0618(99)00046-X

8. Chatveera B and Nimityongskul P. Mechanical properties of sisal fibre-mortar composites containing rice husk ash. In: Fibre Reinforced Cement and Concrete. London: E \& FN Spon; 1992. p. 1056-72.

9. Paramasivam P, Nathan GK and Das Gupta NC. Coconut fibre reinforced corrugated slabs. International Journal of Cement Composites and Lightweight Concrete. 1984; 6(1):19-27. http:// dx.doi.org/10.1016/0262-5075(84)90056-3

10. Lima PRL. Theoretical analysis and experimental characterization of composites reinforced with sisal fibre. [Thesis]. Rio de Janeiro: Federal University of Rio de Janeiro; 2004.

11. Toledo Filho RD. Composite materials reinforced with natural fibres: experimental characterization. [Thesis]. Rio de Janeiro: Pontifical Catholic University of Rio de Janeiro; 1997.

12. Blunt $\mathrm{J}$ and Ostertag C. Deflection hardening and workability of hybrid fibre composites. ACI Materials Journal. 2009; 106:265-272.

13. Jin-Keun K, Jeong-Su K, Ha GJ and Kim YY. Tensile and fibre dispersion performance of ECC (engineered cementitious composites) produced with ground granulated blast furnace slag. Cement and Concrete Research. 2007; 37(7):1096-1105. http://dx.doi.org/10.1016/j.cemconres.2007.04.006

14. Melo Filho JA. Durabilidade Química e Térmica e Comportamento Mecânico de Compósitos de Alto Desempenho Reforçados com Fibras de Sisal. [Thesis]. Rio de Janeiro: Federal University of Rio de Janeiro; 2012.

15. Lima PRL and Toledo Filho RD. Use of metakaolin to improve the durability of sisal fiber- cement based composites. Ambiente Construído. 2008; 8(4):7-19.
16. Yip WK. Generic form of stress-strain equations for concrete. Cement and concrete research. 1998; 28(4):499-508. http:// dx.doi.org/10.1016/S0008-8846(97)00246-9.

17. Fannela DA and Naaman AE. Stress-strain properties of fibre reinforced mortar in compression. ACI Journal. 1985:475-483.

18. Shimizu G and Jorillo P. Coir fibre reinforced cement based composite Part I: Microstructure and Properties of the fibre mortar, In: Symposium 4th Fibre Reinforced Cement and Concrete; 1992; Sheffield. London: E \& FN Spon; 1992; p. 1080-1095.

19. Mazars J. A description of micro- and macroscale damage of concrete structures. Engineering Fracture Mechanics. 1986; 25(5-6):729-737. http://dx.doi. org/10.1016/0013-7944(86)90036-6

20. Lemaitre $\mathbf{J}$ and Mazars J. Application de la théorie de l'endommagement au comportement non linéaire et à la rupture du béton de structures. Annales de l'ITBTP 1982;401:114-138.

21. Comi $\mathrm{C}$ and Perego U. Fracture energy based bi-dissipative damage model for concrete. International Journal of Solids and Structures. 2001; 38(36-37): 6427-54. http://dx.doi. org/10.1016/S0020-7683(01)00066-X

22. American Society for Testing and Materials - ASTM. C230/ C230M-08: Standard Specification for Flow Table for Use in Tests of Hydraulic Cement. ASTM; 2008.

23. American Society for Testing and Materials - ASTM. C 469: Standard Test Method for Static Modulus of Elasticity and Poisson's Ratio of Concrete in Compression. ASTM; 2002.

24. Bhargava P, Sharma UK and Kaushil K. Compressive stressstrain behavior of small scale steel fibre reinforced high strength concrete cylinders. Journal of Advanced Concrete Technology. 2006: 14(1);109-21.

25. Shah SP, Swartz SE and Ouyang C. Fracture mechanics of concrete: applications of fracture mechanics to concrete, rock and other quasi-brittle materials. New York: John Wiley \& Sons Inc.; 1995.

26. Vonk RA. A micromechanical investigation of softening of concrete loaded in compression. Heron. 1993; 38(3).

27. Van Mier JG. Fracture processes of concrete: assesment of material parameters for fracture models. CRC Press; 1997.

28. Savastano H Jr, Santos SF, Radonjic M and Soboyejo WO. Fracture and fatigue of natural fibre-reinforced cementitious composites. Cement and Concrete Composites. 2009; 31(4):232-243. http://dx.doi.org/10.1016/j. cemconcomp.2009.02.006

29. Li Z, Li F, Chang TYP and Mai YM. Uniaxial tensile behaviour of concrete reinforced with randomly distributed short fibres. ACI Materials Journal. 1998; 95(5):564-575.

30. Li VC. A Simplified micromechanical model of compressive strength of fibre reinforced cementitious composites. Journal of Cement and Concrete Composites. 1992; 14(2):131-41. http:// dx.doi.org/10.1016/0958-9465(92)90006-H

31. Mangueira FB, Oliveira Neto L and Azambuja MA. Determination of the numerical parameters of a continuous damage model for the structural analysis of clay brick masonry. Materials Research. 2012; 15(6):1013-1021.

32. Nataraja MC, Dhang N and Gupta AP. Stress-strain curves for steel-fiber reinforced concrete under compression. Cement and Concrete Composites. 1999; 21(5-6):383-90. http://dx.doi. org/10.1016/S0958-9465(99)00021-9

33. Ferreira SR. Influência da hornificação na aderência fibra-matriz e no comportamento mecânico de compósitos cimentíceos reforçados com fibras curtas de sisal. [Dissertation] Feira de Santana: State University of Feira de Santana; 2012. 